\title{
Article
}

\section{Ready for green building risks? The case of South 3 Korea from the architect's point of view}

\author{
Jinho Kim \\ Division of Urban Design and Architecture, Incheon National University, Incheon 22012, South Korea; \\ Jinhokim2015@inu.ac.kr; Tel.: +82-32-835-8981
}

\begin{abstract}
The number of green buildings has increased to address the global environmental crisis. However, green buildings face risks resulting from new materials and methods. In addition, these buildings are expected to perform at higher levels than traditional ones. The objectives of this study are to identify the possible risk factors for architects developing green building projects in South Korea and to assess risk mitigation measures. To attain this goal, fourteen risk factors and twelve mitigation measures were identified from a comprehensive literature review. A questionnaire survey was administered to architects practicing green building design. Findings revealed the 'adoption of new technology and processes' was the largest difference between green and traditional building projects. This study identified 'financial risk,' 'design changes,' and 'client's goal uncertainty' as the top three risk factors in green building design. Additionally, the survey proposed the four most effective risk mitigation measures for green building projects: (1) 'contract indicating each party's roles, liabilities and limitations clearly'; (2) 'utilizing integrated design process'; (3) 'understanding client's goal in green building projects'; and (4) 'improving communication and coordination among stakeholders.' There are a few studies focusing on the architects' perceived risk concerning green building projects; however, this study expands the knowledge and fills the literature gap. Additionally, this study provides a comprehensive understanding of critical risks and mitigation measures that can benefit South Korea's green building design practice through better risk management.
\end{abstract}

Keywords: green building; risk management; risk factors, risk mitigation measures; architect

\section{Introduction}

The rapid increase in the use of fossil fuels that began after the Industrial Revolution has led to global warming and works as a direct cause of climate change [1]. Energy used by buildings accounts for a substantial proportion of carbon dioxide emissions. Evidence shows that buildings consume $40 \%$ of energy and materials, as well as $16 \%$ of water around the world [2]. In the United States, $68 \%$ of electricity consumption, $38 \%$ of carbon dioxide emissions, $39 \%$ of energy consumption, and $12 \%$ of potable water consumption are from buildings [3].

Architecture, Engineering, Construction (AEC) experts and government officials have taken the environmental crisis seriously. The green building concept was introduced to actively address it. According to the Environment Protection Agency (EPA) of the United States, green building is 'the practice of creating structures and using processes that are environmentally responsible and resource-efficient throughout a building's life-cycle from siting to design, construction, operation, maintenance, renovation and deconstruction.' [4]

Consequently, the green building movement is gaining popularity over the traditional buildings in the United States. In 2005, the green building market consisted of only $2 \%$ of all new non-residential construction. By 2010, the number had grown to $28 \%-35 \%$ in the United States [5]. 
Since the United States Green Building Council (USGBC) began full-fledged research on green buildings in 2006, the demand for green buildings remained substantial in 2016. Factors such as client demand, low-cost building operation, and necessity are found to be the factors that will raise the demand for green buildings in the future [6]. Two factors that are considered to be the main drivers of increased demand for green building include participation in resolving global environmental problems and the variety of economic profits these buildings bring.

South Korea is on the threshold of transitioning beyond a developing country to an advanced country. It is one of the countries participating in the Organization for Economic Corporation and Development (OECD) that exhibits a substantial influence on the global economy. As a member of the global society, South Korea has a duty to reduce greenhouse gas emissions according to climate change conventions and has been making diversified efforts to achieve this reduction goal. Notably, the South Korean government has established a basic roadmap for national gas reduction by the year 2030. Essentially, the government is pushing forward with a 37\% national greenhouse gas reduction target against business as usual (BAU). According to this roadmap, South Korea has agreed to reduce a total of 219 million tons of greenhouse gas. Out of that amount, the building sector plans to reduce its production of greenhouse gases by 35.8 million tons, which is $18.1 \%$ of the total reduction target volume. The South Korean government intends to respond more actively to climate change and take the opportunity to shift to a new paradigm of growth [7]. As part of their efforts, the South Korean government announced its Zero Energy Building obligation roadmap in December 2014. According to the timeline, they will begin implementation of the roadmap in the public sector in 2020. A phased implementation in the private sector targets a goal of completion by 2025 [8]. In South Korea, the construction industry occupies a substantial share in the national economy and comprises $8.1 \%$ of the gross domestic production (GDP) [9]. The demand for green buildings and resulting proportion of green buildings will continue to rise in South Korea based on the shift in policy.

In order to meet the rigorous national goal mentioned above, the role of architects is important in the planning, design, construction of not only traditional buildings but also green buildings that require high-quality performance. Architects can assure this high level of quality because they work closely with their clients to discuss the objective, scope, budget, and design of diverse projects from the start. The architect's design work is defined as the development of design documents that consist of drawings and specifications as well as consulting activities. Their work also involves supervision to confirm whether the content in the design document is accurately reflected in the construction process, including tasks related to the construction contract. At that point, architects assist clients to select contractors and administer construction process. They also work with clients in fulfilling diverse administrative tasks related to different approvals and inspections. Based on their professional knowledge and experience, architects perform the design work that materializes into a building and fully considers the client's requirements [10].

As changes in the construction industry shift the focus to the prioritization of green buildings, the government agencies develop regulations to promote them. Accordingly, the architects are then required to acquire a high standard of expertise and responsibility, which eventually affects the architects' 'standard of care.' The standard of reasonable care is the minimum expectation for architects by law and 'the most widespread and generally accepted baseline for evaluating the adequacy of design professional performance' [11]. The AIA B101-2007, Standard Form of Agreement Between Owner and Architect, establishes this standard. Specifically, 'the architect shall perform its services consistent with the professional skill and care ordinarily provided by architects practicing in the same or similar locality under the same or similar circumstances.' The architect shall render its services as expeditiously as is consistent with such professional skill and care and the orderly progress of the project [12].

Traditional buildings were designed and built in a way that complied with minimum legal requirements. However, architects who design green buildings must not only fulfill such requirements, but also achieve better performance expected for green buildings. Green buildings, however, pose risks from the application of relatively newer construction materials, technologies, 
and processes to achieve green building status. The benefits of green building include reductions in the consumption and cost of energy and water, the generation and disposal of construction waste, improved indoor air quality and increased worker productivity. However, if a green building fails to fulfill its performance indices addressed above, this could ultimately lead to a client's dissatisfaction and thereby, conflict.

This study aims to identify and evaluate risk factors and mitigation strategies in green buildings in order to determine a scientific basis for better risk management in the South Korean context. Architects are provided to prepare strategies for the upcoming green building projects by understanding potential risks when practicing green building projects. Additionally, this study contributes to previous literature mainly focused on the risks in the construction industry by suggesting design professionals oriented perspective of view.

This study is detailed in five sections. In Section 2, review of prior literature and hypotheses are addressed. In Section 3, research methods are presented. Section 4 shows a questionnaire survey's results and discussion. Finally, Section 5 summarizes and concludes the paper.

\section{Literature Review and Hypotheses}

Although risk identification studies regarding architectural practice are limited, growing awareness of risks in the green building has been raised. To start, a database search was conducted by using the Scopus database. The search code "(TITLE-ABS-KEY [green building] AND TITLE-ABS-KEY [risk])" was used to search for the articles relating to both green building and risk. An initial review of search results was processed by reading the abstracts and skimming the contents of the articles in order to screen the papers relevant to the research goal. In total, 9 research papers were reviewed thoroughly to identify the risk factors in green building.

One line of literature has investigated cost as the main risk factor in green building design and construction. Gurgun et al. [13] recognized the top risk factors to minimize cost impacts in LEED certified projects: (1) when contractors and subcontractors disagree as to standards within their expertise and competence; (2) the high cost of certification; (3) the lack of expertise in new products, materials and technologies; and (4) inadequate definition of parties to the project's contractual roles and responsibilities. Finally, in using a fuzzy synthetic evaluation approach, Zhao et al. [14] assessed inaccurate cost estimation as the top risk factor. Further, the cost overrun risk was the most critical group in green building projects in Singapore. Al Rumanithi and Beheiry [15] found that utilizing green project management processes could lower the costs and risks of green projects. It could also raise their competitive advantage over conventional projects by presenting the case study in the United Arab Emirates. Chan et al. [16] identified and evaluated 20 barriers to adopt green building technologies in Ghana from a comprehensive literature review. Results from a questionnaire survey performed by green building professionals substantiated that the top three critical barriers were higher initial cost, lack of government incentives, and lack of financing.

Identifying risk factors while comparing traditional and green building was conducted in retrofit and commercial green building projects. Hwang et al. [17] summarized 20 risk factors and 37 mitigation measures associated with green retrofit projects and conducted a questionnaire survey within the context of Singapore. They found that 19 risks were more critical in green retrofits than its traditional counterpart. The top eight risk factors were identified as post-retrofit tenant's cooperation, regulations, market demand, project finance, pre-retrofit tenant's cooperation, and concerns from stakeholders, material supply and availability. Cattano et al. [18] identified that unforeseen conditions were the cause of both schedule delay and cost increase when delivering renovation projects for improved energy performance. Additionally, Cattano et al. [18] proposed the use of a comprehensive building inspection guide that could reduce the risk of unforeseen conditions. Regarding green commercial building projects, Hwang et al. [19] identified the top five critical risk factors after a comprehensive literature and structured interview. Risk factors involve inflation, currency and interest rate volatility that can be worsened by the import of green materials, durability of green materials, damages caused by human error, and shortage of green materials. 
146

147

148

149

150

151

152

153

154

155

156

157

158

159

160

They found that adoptions of green ideas, materials, and technologies had posed additional risks to green commercial projects.

Other researchers have developed stakeholder decision-making models to identify risks in green building. Pearch et al. [20] initiated a study to promote the adoption of green building renovations and employed a process of interactive stakeholder mapping. This process aims to identify possible points of influence for changing stakeholders' decisions about specific innovations in green building and demonstrating the rewards that green building can bring. Similar to these studies, Yang et al. [21] modeled the interactive networks of the risks associated with different stakeholders in green building projects to comprehend the key risk networks. By using social network analysis methods, risk factors are identified differently between China and Australia; specifically, reputation risk is important in both countries. However, the ethical risk of 'assessment experience and fairness' has been highlighted as crucial in the Chinese context. Namely, the government plays a critical role in improving the societies' knowledge and awareness on green technology uptake in China.

Table 1. Risk factors associated with green building design

\begin{tabular}{lll}
\hline Code Risk factors & References
\end{tabular}

R1 Financial risk Grugun et al. [13], Zhao et al. [14], Al Rumanithi and Beheiry [15], Chan et al. [16], Hwang et al. [17], Hwang et al. [19], Marsh [22], Bowers \& Cohen [27], Yudelson [31]

\begin{tabular}{lll}
\hline R2 & Delay in schedule risk & Sloan et al. [24], O'Connor [29], Yudelson [31] \\
\hline R3 & $\begin{array}{l}\text { Building products and } \\
\text { materials }\end{array}$ & $\begin{array}{l}\text { Grugun et al. [13], Al Rumanithi and Beheiry [15], Hwang } \\
\text { et al. [17], Hwang et al. [19], Marsh [22], Odom el al. [23], } \\
\end{array}$ \\
& $\begin{array}{l}\text { Sloan et al. [24], Latham \& Watkins [25], O'Connor [29], } \\
\text { Longley \& Yoakum [33] }\end{array}$ \\
\hline R4 & New technology and process & Grugun et al. [13], Al Rumanithi and Beheiry [15], Hwang
\end{tabular}
Grugun et al. [13], Al Rumanithi and Beheiry [15], Hwang et al. [19], Yang et al. [21], Marsh [22], Odom el al. [23], Latham \& Watkins [25], Bowers \& Cohen [27], Wendt [28], Hwang et al. [18]

\begin{tabular}{cll}
\hline R5 & Design guideline availability & Han \& Kim [35] \\
\hline R6 & Energy saving uncertainty & $\begin{array}{l}\text { Hwang et al. [18], Kubba [32], Longley \& Yoakum [33], } \\
\text { Tollin [34] }\end{array}$ \\
\hline R7 & Green building certification & $\begin{array}{l}\text { Sloan et al. [24], Anderson et al. [26], Bowers \& Cohen } \\
\text { [27], Wendt [28], O'Connor [29], Yudelson [31], Kubba } \\
\text { [32], Longley \& Yoakum [33], Tollin [34] }\end{array}$ \\
\hline R8 & Team performance risk & $\begin{array}{l}\text { Grugun et al. [13], Hwang et al. [18], Yang et al. [21], } \\
\text { Marsh [22], Wendt [28], O'Connor [29], Longley \& } \\
\end{array}$ \\
& & Yoakum [33], Tollin [34] \\
\hline R9 & Client's goal uncertainty & Sloan et al. [24], Wendt [28], O'Connor [29], Longley \& \\
& & Yoakum [33] \\
\hline R10 & Regulatory/Legislative risk & $\begin{array}{l}\text { Hwang et al. [17], Yang et al. [21], Marsh [22], Sloan et al. } \\
\text { [24], Longley \& Yoakum [33] }\end{array}$ \\
\hline R11 & Design changes & Anderson et al. [26], O'Connor [29] \\
\hline R12 & Lack of communications & Sloan et al. [24], O'Connor [29] \\
\hline R13 & Incomplete drawings \& specs & Cattano et al. [18], Keen [30], Tollin [34] \\
\hline R14 & Lack of contract & Grugun et al. [13], Marsh [22], Anderson et al. [26], \\
& & Bowers \& Cohen [27], Wendt [28] \\
\hline
\end{tabular}

As demonstrated above, the literature review provides a solid foundation for identification of risks in green building. In addition to those noted academic journals, nine additional articles from AEC industry trade journals, white papers [22-30], three published books [31-33], and one 
additional academic journals [34,35] are added to supplement the risks found in architectural' design and consulting services. Finally, the total 23 literatures are categorized according to the classical elements of project management: (1) cost, (2) schedule, and (3) quality. This quality attribute is subdivided in terms of factors affecting production of design drawings (R5, R10), design quality (R11, R13) and consulting services (R8, R9, and R12). Performance risks have been added in order to evaluate the performance of materials and technology applied in the building as well as results of any energy savings in green building certification level (R3, R4, R6, and R7). Contracts without clear lines of responsibilities, roles, and limitations have been added into one of the risk factors since it is a means to prevent legal and administrative risk that can lead to a claim (R14). As a result, fourteen risk factors were identified to conduct a subsequent questionnaire as shown in Table 1.

Although these studies provide some evidence of comprehensive studies of green building risk, our knowledge regarding the risk perceptions of architects within the context of service scope remains limited. Therefore, the objective of this study is to answer the following questions: (1) Do differences exist in South Korean architect's perceived risk factors in terms of designing traditional building and green building?; (2) How do the risk factors for traditional building and green buildings rank?; and (3) What are the effective risk mitigation measures perceived by South Korean architects and how do they rank? To date, research has been conducted on green building risks in terms of construction management, but there have been few studies on the risk factors perceived by architects themselves. Therefore, by shedding light on architect perception, this study will ultimately contribute to the improvement of the quality in green buildings, thereby helping to further advance the construction industry.

\section{Methods}

\subsection{Data collection and presentation}

For this study, a questionnaire survey was administered to compare the risk factors and risk mitigation measures for traditional buildings and green buildings as perceived by South Korean architects. Regarding the risk factors, the risk occurrence likelihood and their degree of impact on traditional buildings and green buildings were examined separately.

Before beginning the questionnaire survey, it was mandated that the scope of green buildings include those that obtained the following: Green Standard for Energy and Environmental Design (G-SEED), Korean green building rating system; Leadership in Energy and Environmental Design (LEED), another green building rating system developed by the U.S. Green Building Council; the Building Energy Efficiency Certificate and Zero Energy Building Certificate developed and administered by Korea Energy Agency; the Passive Construction Certificate of Passive House Institute Korea. In addition, before it was distributed to respondents, the questionnaire was reviewed overall by two experts who have full knowledge in questionnaire survey methodology, as well as by an architect who has more than 10 years of experience in architectural design.

After undergoing a revision process for survey items and questions, the final version of the questionnaire was written using Google Survey [36]. The subject of the survey was South Korea's leading architectural design firms which are ranked within $15^{\text {th }}$ in sales volume from Korea Financial Supervisory Service. Among them, 10 companies able to answer the questionnaire were selected; the number of respondents from each company was limited to 20 staff members working in architectural design. The questionnaire was sent through e-mail in February 2018 and respondents were given four weeks to answer. Weekly reminders were sent via phone or e-mail to encourage respondents to answer the questionnaire. A total of 96 questionnaire copies were collected, three of which were excluded due to insufficient answers. A total of 93 copies of the questionnaire were analyzed. The response rate for the questionnaire survey was $47.5 \%$.

Table 2 shows the distribution of respondent's experiences in the field. As shown, $74.1 \%$ of the respondents had more than five years of experience in designing traditional buildings, while $52.6 \%$ had more than three years' experience in designing green buildings. Such distribution proves that 
215

216

217

218

the respondents had sufficient experience for the study's objective and that the collected data was representative.

Table 2. Profiles of survey respondents

\begin{tabular}{ccc}
\hline Profile & Frequency & Percentage \\
\hline Years of experience in traditional building projects & & \\
Less than one year & 3 & 3.2 \\
1 to 2 years & 4 & 4.3 \\
3 to 4 years & 17 & 18.2 \\
5 to 10 years & 29 & 31.1 \\
More than ten years & 40 & 43.0 \\
\hline Years of experience in green building projects & & \\
Less than one year & 26 & 27.9 \\
1 to 2 years & 18 & 19.3 \\
3 to 4 years & 20 & 21.5 \\
5 to 10 years & 23 & 24.7 \\
More than ten years & 6 & 6.4 \\
\hline
\end{tabular}

Table 3. Rating scales for LO and MI

\begin{tabular}{ccccc}
\hline & \multicolumn{2}{c}{ Likelihood of Occurrence } & \multicolumn{2}{c}{ Magnitude of Impact } \\
LO & Linguistic Terms & Likelihood of References & MI & Linguistic Terms \\
\hline 1 & Rare & $<20 \%$ & 1 & Insignificant \\
2 & Unlikely & $20 \%-40 \%$ & 2 & Minor \\
3 & Moderate & $40 \%-60 \%$ & 3 & Moderate \\
4 & Likely & $60 \%-80 \%$ & 4 & Major \\
5 & Almost certain & $>80 \%$ & 5 & Catastrophic \\
\hline
\end{tabular}

\subsection{Criticality index}

To evaluate the criticality of each risk, this study adopted the risk criticality (RC) index used in previous relevant studies [37-41]. This RC index has been extensively perceived as the function of the likelihood (LO) of occurrence and magnitude (MI) of impact. In this study, respondents were asked to assess the LO and MI using five-point Likert scales as shown in Table 3. By using equations (1), (2), (3), and (4), LO, MI, and RC can be measured respectively:

$$
\begin{aligned}
& L O^{i}=\frac{1}{n} \sum_{j=1}^{n} L O^{i}, \\
& M I^{i}=\frac{1}{n} \sum_{j=1}^{n} M I_{j}^{i},
\end{aligned}
$$

where $\mathrm{n}=$ the total number of respondents, $\mathrm{LO}^{\mathrm{i}}=$ the likelihood assessment of risk $i, \mathrm{LO}_{j}^{\mathrm{i}}=$ the likelihood assessment of risk $i$ by respondent $j, \mathrm{MI}^{\mathrm{i}}=$ the magnitude assessment of risk $i$, and $\mathrm{MI}_{j}^{\mathrm{i}}=$ the magnitude assessment of risk $i$ by respondent $j$ [37].

$$
\begin{aligned}
& R C_{j}^{i}=L O_{j}^{i} \times M I_{j}^{i}, \\
& R C^{i}=\frac{1}{n} \sum_{j=1}^{n} R C_{j}^{i},
\end{aligned}
$$

where $\mathrm{n}=$ the total number of respondents, $\mathrm{RC}_{j}^{\mathrm{i}}=$ the risk criticality of risk $i$ by respondent $j$, and $\mathrm{RC}^{\mathrm{i}}=$ the risk criticality of risk $i$ [37]. 


\section{Results and discussions}

\subsection{Risk criticalities: Traditional versus Green Building Projects}

As actively practicing architectural design service in South Korea, the respondents were asked to evaluate the LO and MI for the 14 risk factors. RC values, ranking, and difference were calculated between green and traditional projects as shown in Table 4 . The paired t-test was used to verify the difference in RC values between the two groups. The results showed that p-values of 6 risk factors were below 0.05 , suggesting that there were significant differences in RC values between green and traditional projects. The RC values of these 6 risks in green projects were higher than those in traditional projects, suggesting that the research hypothesis was supported.

Table 4. Comparison of RC values between green and traditional building projects.

\begin{tabular}{ccccccc}
\hline \multirow{2}{*}{ Code } & \multicolumn{2}{c}{ Green } & \multicolumn{2}{c}{ Traditional } & \multicolumn{2}{c}{ Wilcoxon signed-Rank Test } \\
\cline { 2 - 7 } & RC & Rank & RC & Rank & Difference & p-Value \\
\hline R1 & 16.1 & 1 & 15.18 & 3 & 0.92 & $0.019^{*}$ \\
R11 & 15.23 & 2 & 16.47 & 1 & -1.24 & 0.069 \\
R9 & 15.19 & 3 & 15.35 & 2 & -0.16 & 0.733 \\
R10 & 14.6 & 4 & 13.05 & 5 & 1.55 & 0.217 \\
R2 & 14.57 & 5 & 14.44 & 4 & 0.13 & 0.710 \\
R14 & 13.56 & 6 & 12.84 & 7 & 0.72 & 0.118 \\
R12 & 13.05 & 7 & 13.05 & 5 & 0 & 0.951 \\
R8 & 12.8 & 8 & 11.66 & 8 & 1.14 & 0.097 \\
R5 & 12.46 & 9 & 11.43 & 9 & 1.03 & 0.136 \\
R13 & 12.08 & 10 & 10.99 & 10 & 1.09 & $0.048^{*}$ \\
R6 & 12.03 & 11 & 10.38 & 11 & 1.65 & $0.005^{*}$ \\
R3 & 11.75 & 12 & 9.80 & 12 & 1.95 & $0.001^{*}$ \\
R4 & 11.73 & 13 & 8.76 & 14 & 2.97 & $0.000^{*}$ \\
R7 & 10.98 & 14 & 8.82 & 13 & 2.16 & $0.000^{*}$ \\
\hline
\end{tabular}

${ }^{*}$ indicates the paired $t$-test result is significant at the 0.05 significance level.

The risk 'R4-Adoption of new technologies and process' indicates the largest difference (Diff.=2.97). Contemporary green building is relatively young, with innovative new approaches and technologies introduced to improve building performance. These recent practices, however, add a layer of complexity that requires diligent maintenance and monitoring to prevent potential water or moisture issues that could damage the building's integrity. For example, installation of green roof, the practice of increased ventilation and building flush out, and increased insulation within the exterior walls which change the location of the dew point, can bring unintended moisture into the building, resulting in mold issues, especially in hot and humid climates [23]. Architect needs to make decisions of their applications based on technical data from the manufacturer and to test and evaluate its effectiveness using mock-ups before applying in the construction fields [26]. Communication among project stakeholders is essential; architects needs to inform any risks uncovered during the selection process and to discuss contractors with any potential issues during construction phase.

The risk 'R7-Green Building Certification Results' has the second largest difference (Diff.=2.16). Green building rating system such as G-SEED or LEED performs the evaluation per each criteria and gives the final grade for the purpose of an objective evaluation by a third party. In addition, the certification grade can be a very sensitive issue for clients who are the beneficiary of green buildings, as the tax benefit or incentive granted to them can differ according to the result of the certification. There exists a likelihood of dispute between architects and clients if the final grade is lower than expected or the certification itself fails. It is recommended that architects refrain from making assurances about the level of certification a building will attain. If an architect warrants that 
264

265

266

267

268

269

270

271

272

273

274

275

276

277

278

279

280

281

282

283

284

285

286

287

288

289

290

291

292

293

294

295

296

297

298

299

300

301

302

303

304

305

306

307

308

309

310

311

312

313

314

a building will achieve a specific level of certification, they may assume a high amount of risks based on the fact that insurance companies often do not cover such warranties [34,42].

The risk 'R3-Building products and materials' has the third largest difference (Diff.=1.95). Some green products are in high demand and low supply, which results in a long lead time, thereby affecting the project schedule. Additionally, use of salvaged materials in new projects, the use of recycled content materials, and selection of locally produced buildings materials is highly encouraged to reduce the environmental footprint associated with extraction, production, and transportation of the building materials. However, the performance of new products can create a risk since they are developed without enough time to field test. When these untested products fail to meet the expected levels of performance, this can lead to legal disputes over who is responsible. In order to prevent potential liability issues out of specifying green products and materials, architects have a duty to discuss untested or new products with the client. Additionally, they must describe any possible impacts on the project, including, but not limited to, product performance and achieving an expected green building certification level. Language in the contract should address the issue of risks of new materials in order to protect architects from claim. Examples may include (1) "the owner will render a decision [about untested materials] and (2) the architect shall be permitted to rely on the manufacturers' or suppliers' representations and shall not be responsible for any failure of the Project to achieve the Sustainable Objective as a result of the use of such materials or equipment [43]."

The risk 'R6-Energy Saving Uncertainty' has the fourth largest difference (Diff.=1.65). When considering a building's operational performance, clients and tenants tend to expect that green buildings will reduce environmental impacts, reduce energy and water costs, and involve less maintenance and other long-term benefits to the building owner. Energy efficiency is one of the most compelling green building performance factors to reduce operating costs. However, there are too many factors beyond the control of the architects to meet energy saving goals. Most of all, even though architects incorporate green features into the building, there is a considerable gap between design and occupancy. Any outcome in energy consumption is predicated based on assumptions which need to be understood by the owner, facilities manager, and tenants who must properly operate and maintain the equipment systems. It is recommended architects hire a commissioning agent before and after construction to catch potential problems as necessary to achieve the planned energy savings [28].

The risk 'R13-Incomplete drawings and specifications' ranked the fifth (Diff.=1.09). Contract documents consist of drawings and specifications as well as related supplementary paper work. Incomplete contract documents result from unclear and inadequate documentation, insufficient site investigation, and design changes [30]. This ultimately results in design changes and an increase in construction cost and period of time it takes to build. As green buildings require higher performance than traditional buildings, thereby bearing high complexity [44,45], a greater influence is exerted onto green buildings than traditional buildings in case the design documents and specifications are not perfectly matched.

The statistical analysis results from this study's questionnaire survey revealed similarities between the risk factors for green buildings and the risk factors for traditional buildings in R1-Financial risk, R11-Design changes, R9-Client's goal uncertainty, R10-Regulatory and legislative risk, R2-Delay in schedule risk, R14-Lack of contract, and R12-Lack of communications.

The result of the Wilcoxon-rank test verified that R1-Financial Risk was the primary risk factor for green buildings that differed from traditional buildings. Diverse factors that arise in the process of pushing forward with green building design and construction are thought to be the cause. The factors involved in financial risks likely include the following: design change due to the client's unexpected new direction, the architect's lack of experience and knowledge of the system of green buildings; unexpected increases in budget or cost that consequently occur; and increase in the budget following the selection of products and materials available to fulfill green building certification standards. In short, (1) the risk factors for traditional buildings are also relevant as 
green buildings risk factors; and (2) unlike traditional buildings, the budget impact could be an additional risk for green buildings.

\subsection{Proposed risk mitigation measures}

This study also surveyed respondents to assess the efficiency of the 12 risk mitigation measures developed from the literature. Table 5 shows the 12 risk mitigation measures as ranked to tackle risks associated with green building design service in South Korea. Mitigation measures above 3.85 values are discussed as follows.

Table 5. Risk mitigation measures in green building projects in South Korea.

\begin{tabular}{lccc}
\hline \multicolumn{1}{c}{ Code } & Risk Mitigation Measure & Mean & Rank \\
\hline RMM8 & Contract indicating each parties' role, liability and limitations clearly & 3.93 & 1 \\
RMM11 & Utilizing integrated design process & 3.9 & 2 \\
RMM9 & Understanding client's goal in green building projects & 3.88 & 3 \\
RMM7 & Improving communication and coordination among stakeholders & 3.86 & 4 \\
RMM2 & Using previous successful green building projects as reference & 3.83 & 5 \\
RMM10 & Quality control for construction drawings and specifications & 3.83 & 6 \\
RMM1 & Contingency funds in case of emergency & 3.82 & 7 \\
RMM6 & Effective management system for design changes & 3.75 & 8 \\
RMM3 & Investing in research on green building materials and processes & 3.69 & 9 \\
RMM5 & Development of education programs for team members & 3.58 & 10 \\
RMM4 & Adoption of commissioning agent & 3.52 & 11 \\
RMM12 & Purchase of insurance at risk allocation & 3.45 & 12 \\
\hline
\end{tabular}

The risk mitigation measure 'RMM8-Contract indicating each party's role, liability and limitations clearly' was assessed as the most effective measure with the highest evaluation of 3.93. Many disputes arise from miscommunications and misunderstandings on roles, responsibilities, and limitations that could be lessened by using precise contract language. The contracting parties should clearly define the scope of work, schedule, building performance expectations, certification levels, and risk allocation in their contracts [25]. AIA Document 'D503-2013 Guide for Sustainable Projects' developed by the AIA can be considered as a reference guide [43].

The risk mitigation measure 'RMM11-Utilizing integrated design process' scored the second-highest value at 3.9. The process of an integrated design process (IDP) represents the prospect for risk reduction by architects in a green building project. The traditional delivery method is the design-bid-build process in which the client contracts with separate entities for design and construction. Specifically, the project is designed by separate teams of architects and engineers and then put out for bidding to general contractors. The contractors build the project according to developed designs. However, this project delivery method is not ideal when employing an IDP because it may discourage collaboration among parties involved in construction projects. In contrast to traditional processes, the integrated design processes can pull together a multi-disciplinary team of architects, consultants, clients, tenants, contractors to work from the project's start and promote better communication. The goal of the IDP is to optimize the building's performance while reducing any rework, delay, and cost overrun that can challenge a successful green building project with complicated systems and technologies. Alternative project delivery methods can facilitate the integrated design process $[27,28,46]$ and close collaboration; specifically, adoption of design-build contracts, construction managers at-risk, and integrated project delivery (IPD).

The risk mitigation measure 'RMM9-Undertanding client's goal in green building projects' received the third highest value at 3.88 in the effectiveness evaluation. It is highly recommended that clients establish sustainability goals, the level of certification where relevant, and related project requirements in the early design stage. Identifying client's goals and expectations ultimately 
reduces the potential for misunderstanding among clients, architects, and contractors, defines clear goals and responsibilities in the design process and provides the potential to reduce project time and costs resulting from miscommunications among related parties.

The risk mitigation measure 'RMM7-Improving communication and coordination among stakeholders' was assessed as the fourth most effective measure with an evaluation of 3.86. It is important to assure the flow of information throughout the project development process in order to reduce defects in design and construction. This is particularly prudent where some parties may be new to green building. Measures to assure information flow include: (1) holding meetings with the design team to review project requirements and goals; (2) clarifying additional documentation and other certification-related requirements particularly with general contractors and attorneys; (3) holding meetings with general contractors, subcontractors, and attorneys to ensure that they understand the purpose of green-related requirements; and (4) providing additional training and materials to subcontractors where necessary [27]. 'The greatest risk management tool is reaching understanding and clear communication between the architect, owner, and contractor' [24]. Such mutual understanding requires in-depth collaboration among parties to minimize the potential risks associated with new practice with innovative technologies and materials applied in the green building design.

\section{Conclusions}

The demand for green building has increased in recent years due to global crisis and benefits from saving related to energy and natural resources. However, this relatively new practice is exposed to potential risks generated from new materials and methods, along with raised expectations of higher performance than that of traditional buildings.

This study first conducted a questionnaire survey to determine the risk factors associated with the green building design services in South Korea from the architect's point of view. The findings revealed that 'adoption of new technology and process' had the largest difference in criticality between green and traditional building projects. Furthermore, this study identified 'financial risk,' 'design changes,' and 'client's goal uncertainty' as the top three critical factors in green building design.

In addition, the survey identified the four most effective risk mitigation measures in green building projects: 'contract that clearly indicates each party's role, liability, and limitations,' 'utilizing integrated design processes,' 'understanding client's goal in green building project,' and 'improving communication and coordination among stakeholders.' In order to avoid potential risks for a green building project, the integrated design process must be based on open communications. Additionally, contracts must clearly define performance expectations.

Despite these are two basic limitations inherent in this study. First, the respondent resource used in the survey is confined to major architectural design firms only. The architects' working in small or mid-sized firms has been excluded. Thus, careful attention should be given when the results from the analysis are generalized and applied. Second, findings from this study apply to South Korea exclusively, which in turn, may vary from other counties in different conditions.

In this study, this is the first time mitigation measures and diverse risk factors which affect the architects' practice have been investigated in green building projects. Thus, in spite of limitations addressed above, findings from this study are still beneficial. This study has provided the foundation to benefit South Korea's green building industry by means of better risk management. By analyzing potential risks that are foreseeable and taking reasonable precautions, architects are able to minimize exposure to losses and potential disputes. By including architecture, industry practitioners in engineering and construction can obtain a deeper understanding of potential risks in green building projects. In doing so, they prepare a customized checklist and strategies for the upcoming green building projects.

Three research topics can be suggested for future research subjects: (1) comparison studies that assess and identify the risk factors perceived between architects and contractors or between South Korea and other countries within the same profession; (2) systematic risk mitigation guideline 
402

403

404

405

406

407

408

409

410

411

412

413

414

415

416

417

418

419

420

421

422

423

424

425

426

427

428

429

430

431

432

433

434

435

436

437

438

439

440

441

development based on collecting and analyzing the legal cases involving green building design and construction; and (3) identifying risk factors and effective risk mitigation measures through in-depth interviews with AEC industry professionals.

Acknowledgments: This research was made possible by financial support of the Incheon National University newly appointed faculty grant. Project number: 2015-1821

Conflicts of Interest: The author declares no conflict of interest.

\section{Appendix A. Questionnaire Used for This Study}

Section 1: Background Information of Respondent

1. Please select your age range
A. Twenties
B. Thirties
C. Forties
D. Fifties
E. Sixties and older

2. Are you currently employed in the architectural design firm?
A. Yes
B. No

3. Please identify the number of green building projects
A. Less than 5
B. 5 to 10
C. 11 to 15
D. More than 20

4. Please identify your years of experience in architectural design service
A. Less than 1
B. 1 to 2 years
C. 3 to 4 years
D. 5 to 10 years
E. More than 10 years

5. Please identify your years of experience in green building design service
A. Less than 1
B. 1 to 2 years
C. 3 to 4 years
D. 5 to 10 years
E. More than 10 years

Section 2: Assessment of Risks of Traditional Building Design Service

Based on your design experience in traditional building projects, please evaluate each risk factor below in terms of its likelihood and magnitude of impact using five-point Likert scales:

Likelihood of occurrence: 1-Rare; 2-Unlikely; 3-Moderate; 4-Likely; 5-Almost certain.

Magnitude of impact: 1-Insignificant; 2-Minor; 3-Moderate; 4-Major; 5-Catastrophic.

\begin{tabular}{lllllllllll}
\hline \multirow{2}{*}{ Code } & \multicolumn{3}{c}{ Likelihood of Occurrence } & \multicolumn{3}{c}{ Magnitude of impact } \\
\cline { 2 - 9 } & 1 & 2 & 3 & 4 & 5 & 1 & 2 & 3 & 4 & 5
\end{tabular}

Financial risk

Delay in schedule risk

Building products \& materials

New technology and process 


\begin{abstract}
Design guidelines availability
Energy saving uncertainty

Green building rating results

Team performance risk

Client's goal uncertainty

Regulatory/Legislative risk

Lack of communications

Incomplete drawings \& specs

Lack of contract
\end{abstract}

Section 4: Assessment of Risk Mitigation Measures for Green Building Design Service

\section{Section 3: Assessment of Risks of Green Building Design Service} below in terms of its likelihood and magnitude of impact using five-point Likert scales: Likelihood of occurrence: 1-Rare; 2-Unlikely; 3-Moderate; 4-Likely; 5-Almost certain. Magnitude of impact: 1-Insignificant; 2-Minor; 3-Moderate; 4-Major; 5-Catastrophic.

\begin{tabular}{|c|c|c|c|c|c|c|c|c|c|c|c|}
\hline \multirow{2}{*}{ Code } & \multirow{2}{*}{ Risk Factors } & \multicolumn{5}{|c|}{ Likelihood of Occurrence } & \multicolumn{5}{|c|}{ Magnitude of impact } \\
\hline & & 1 & 2 & 3 & 4 & 5 & 1 & 2 & 3 & 4 & 5 \\
\hline \multicolumn{12}{|c|}{ Financial risk } \\
\hline \multicolumn{12}{|c|}{ Delay in schedule risk } \\
\hline \multicolumn{12}{|c|}{ Building products \& materials } \\
\hline \multicolumn{12}{|c|}{ New technology and process } \\
\hline \multicolumn{12}{|c|}{ Design guidelines availability } \\
\hline \multicolumn{12}{|c|}{ Energy saving uncertainty } \\
\hline \multicolumn{12}{|c|}{ Green building rating results } \\
\hline \multicolumn{12}{|c|}{ Team performance risk } \\
\hline \multicolumn{12}{|c|}{ Client's goal uncertainty } \\
\hline \multicolumn{12}{|c|}{ Regulatory/Legislative risk } \\
\hline \multicolumn{12}{|c|}{ Lack of communications } \\
\hline \multicolumn{12}{|c|}{ Incomplete drawings \& specs } \\
\hline & Lack of contract & & & & & & & & & & \\
\hline
\end{tabular}
mitigation measures regarding their effectiveness, using five-point Likert scales: Effectiveness: 1-Totally ineffective; 2-Ineffective; 3-Neutral; 4-Useful; 5-Very useful.

Based on your design experience in green building projects, please evaluate each risk factor

Based on your design experience in green building projects, please evaluate the following risk

\begin{tabular}{llllll}
\hline \multirow{2}{*}{ Code } & Risk Mitigation Measures & \multicolumn{3}{c}{ Effectiveness } \\
\cline { 2 - 5 } & 1 & 2 & 3 & 4 & 5
\end{tabular}

RMM1 Contingency funds in case of emergency 
RMM2 Using previous successful green building projects as reference

RMM3 Investing in research on green building materials and processes

RMM4 Adoption of commissioning agent

RMM5 Development of education programs for team members

RMM6 Effective management system for design changes

RMM7 Improving communication and coordination among stakeholders

RMM8 Contract indicating each party's role, liability, and limitations clearly

RMM9 Understanding client's goal in green building project

RMM10 Quality control for construction drawings and specifications

RMM11 Utilizing integrated design process

RMM12 Purchase of insurance at risk allocation

\section{References}

1. Intergovernmental Panel on Climate Change (IPCC). IPCC Fifth Assessment Report. Available online: http://www.ipcc.ch/pdf/assessment-report/ar5/syr/AR5 SYR FINAL SPM.pdf (accessed on 14 March 2018).

2. Roodman, D.M.; Lenssen, N. Worldwatch Paper\#124: A building revolution: How ecology and health concerns are transforming construction. Available online: http://www.worldwatch.org/node/866 (accessed on 14 March 2018).

3. United States Environmental Protection Agency. Why build green? Available online: https://archive.epa.gov/greenbuilding/web/html/whybuild.html (accessed on 14 March 2018).

4. United States Environmental Protection Agency, Definition of green building Available online: https://archive.epa.gov/greenbuilding/web/html/about.html (accessed on 14 March 2018).

5. McGraw Hill Construction. Green outlook 2011: Green trends driving growth. Available online: https://www.bdcnetwork.com/green-building-market-grows-50-two-years-green-outlook-2011-report (accessed on 14 March 2018).

6. Dodge Data \& Analytics. Smart Market report: World green building trends 2016. Available online: http://fidic.org/sites/default/files/World\%20Green\%20Building\%20Trends\%202016\%20SmartMarket\%20R eport\%20FINAL.pdf (accessed on 14 March 2018).

7. Ministry of Environment. 2030 National Greenhouse Gas Reduction Basic Roadmap of South Korea. Available online: http://www.me.go.kr (accessed on 14 March 2018).

8. Korea Energy Agency. Certification of Zero Energy Building of South Korea. Available online: http://www.kemco.or.kr/web/kem home new/ener efficiency/building 08.asp (accessed on 14 March 2018).

9. The Bank of Korea. 2016 Annual Report. Available online: http://www.conslove.co.kr/news/articleView.html?idxno=1041 (accessed on 14 March 2018).

10. The Construction Specification Institute. The Project Resource Manual, 5th ed.; McGraw-Hill, New York, NY, USA, 2005; pp.4.1-4.82, ISBN 0-07-137004-8.

11. Hatem, D.J. Green and sustainable design part I: Professional liability risk and insurability issues for design professionals; Donovan Hatem LLP: Boston, MA, USA, 2010.

12. AIA. B101-2007 Standard Form of Agreement Between Owner and Architect. Available online: https://www.aiacontracts.org/contract-documents/21392-owner-architect-agreement (accessed on 14 March 2018).

13. Gurgun, A.P.; Arditi, D.; Vilar, P.C. Impacts of construction risk on costs in LEED-certified projects. J Green Build. 2016, 11, 163-181. doi:10.3992/jgb.11.4.163.1

14. Zhao, X.; Hwang, B.G.; Gao, Y. A fuzzy synthetic evaluation approach for risk assessment: A case of Singapore's green projects. J. Clean. Prod. 2016, 115, 203-213. doi:10.1016/j.jclepro.2015.11.042

15. Al Rumaithi, K.H.; Beheiry, S.M. A framework for green project management processes in construction projects. International Journal of Sustainable Society. 2016, 8, 126-144. doi:10.1504/IJSSOC.2016.077514 
16. Chan. A.P.C.; Darko, A.; Olanipekun, A.O.; Ameyaw, E.E. Critical barriers to green building technologies adoption in developing countries: The case of Ghana. J. Clean Prod. 2018, 172, 1067-1079. doi:10.1016/j.jclepro.2017.10.235

17. Hwang, B.G.; Zhao, X.; See, Y.L.; Zhong, Y. Addressing risks in green retrofit projects: The case of Singapore. Proj. Mang. J. 2015, 46, 76-89. doi:10.1002/pmj.21512

18. Cattano, C.; Valdes-Vasquez, R.; Klotz, L. Barriers to the delivery of building renovations for improved energy performance: A literature review and case study. In Proceedings of the International Conference on Sustainable Design and Construction 2011, Kansas City, MO, United States, March 2011; pp.203-210.

19. Hwang, B.G.; Shan, M.; Supa'at, N.N.B. Green commercial building projects in Singapore: Critical risk factors and mitigation measures. Sustain. Cities and Soc. 2017, 30, 237-247. doi:10.1016/j.scs.2017.01.020

20. Pearce, A.R.; Doshi, P.; Carneal, M.G. Leverage points for sustainability: Targeting stakeholders, innovations, and decision types of maximal influence. In Proceedings of Construction Research Congress 2016: Old and New Construction Technologies Converge in Historic San Juan, CRC 2016, San Juan, Puerto Rico, May 2016; pp.1181-1191.

21. Yang, R.J.; Zou, P.Z.W.; Wang, J. Modelling stakeholder-associated risk networks in green building projects. Int. J. Proj. Manag. 2016, 34, 66-81. doi:10.1016/j.ijproman.2015.09.010

22. Marsh Group Inc. Green building: Assessing the risks. Available online https://c.ymcdn.com/sites/acrel.site-ym.com/resource/collection/D1CFEE37-A66B-4712-9DFC-6687A87B1 FD9/Maloney ACREL Exhibit 3.pdf (available at 14 March 2018).

23. Odom, J.D.; Scott, R.; DuBose, G.H. The hidden risks of green buildings. Available online: http:/www.buildingforensicsgroup.com/wp-content/uploads/2016/06/NCARB-MIni-Hidden-Risks-Of-Gr een-Buildings No-Covers.pdf (available at 14 March 2018).

24. Slone, D.; McGlamery K.; Blake, D.; York, J. The legal risk in building green: New wine in old bottles? USGBC Panel Discussion, Washington, D.C., USA, 2009.

25. Latham \& Watkins Environment, Land \& Resource Department. Green building projects: The growing trend brings both opportunities and potential liability risks. Available online: https://www.lw.com/thoughtLeadership/risks-in-growing-trend-of-green-building-projects (available at 14 March 2018).

26. Anderson, M.K.; Bidgood, J.K.; Heady, E.J. Hidden legal risks of green building, Fla. Bar. J. 2010, 84, 35-41.

27. Bowers, K.; Cohen, L. The Green Building Revolution: Addressing and Managing Legal Risks and Liabilities; Harvard Law School, Environmental Law \& Policy Clinic, 2009.

28. Wendt, A. Will I get sued? Managing risk in green building. Available online: https://www.buildinggreen.com/feature/will-i-get-sued-managing-risk-green-building (accessed on 14 March 2018).

29. O'Connor, H. Architect's professional liability risks in the realm of green buildings. Available online: https://uk.perkinswill.com/files/ID\%204_PWRI_Vol0402 03 Architect\%E2\%80\%99s\%20Professional\%20L iability\%20Risks\%20in\%20the\%20Realm\%20of\%20Green\%20Buildings.pdf (accessed on 14 March 2018).

30. Keen, B. The pitfalls of incomplete contract documents. Available online: https://www.revay.com/index.php/publications/the-revay-report (accessed on 14 March 2018).

31. Yudelson, J. Reinventing green building: Why certification systems aren't working and what we can do about it, 1 st ed.; New Society Publishers: Gabriola Island, Canada, 2016; pp87-135, ISBN978-0-86571-815-9.

32. Kubba, S. Handbook of green building design and construction, 2nd ed.; Butterworth-Heinemann, Cambridge, MA, USA, 2017; pp.853-897, ISBN 978-0-12-810433-0.

33. Longley P.G.; Yoakum, S.E. Risk and Emerging Practices. In The Architect's handbook of professional practice, 15th ed.; Hayes, R.L., Klein, R.M., Eds.; John Wiley \& Sons: Hoboken, NJ, USA, 2014; pp. 1021-1029, ISBN 978-1-118-30882-0.

34. Tollin, H.M. Green building risks: It's not easy being green. Environ. Claim. J. 2011, 23, $199-213$. doi:10.1080/10406026.2011.593442.

35. Han, J.H.; Kim, S.S. Architectural professionals' needs and preferences for sustainable building guidelines in Korea. Sustainability, 2014, 6, 8379-8397. doi:10.3390/su6128379

36. https://goo.gl/forms/GLbBasdHNH9ZpF1A2 (accessed on 14 March 2018).

37. Hwang, B.G.; Shan, M.; Chi, S. An exploratory analysis of risks in green residential building construction projects: The case of Singapore. Sustainability. 2017, 9, 1116. doi:10.3390/su9071116 
38. Hwang, B.G.; Zhu, L.; Ming, J.T.T. Factors affecting productivity in green building construction projects: The case of Singapore. J. Manage. Eng. 2016, 33, 04016052. doi:10.1061/(ASCE)ME.1943-5479.0000499.

39. Ke, Y.; Wang, S.; Chan, A.P.C.; Cheung, E. Understanding the risks in China's PPP projects: Ranking of their probability and consequence. Eng. Constr. Archit. Manag. 2011, 18, 481-496. doi.:10.1108/09699981111165176.

40. Zou, P.X.W.; Zhang, G.; Wang, J. Understanding the key risks in construction projects in China. Int. J. Proj. Manag. 2007, 25, 601-614. doi:10.1016/j.ijproman.2007.03.001.

41. Hwang, B.G.; Ming, J.T.T. Productivity improvement strategies for green construction projects: Performance comparison and critical factors. International. Journal of Sustainable Building Technology Urban Development. 2017, 8, 45-53. doi:10.12972/susb.20170004.

42. Huston, M.D. Sustainable building: Anticipate potential liability to manage risk. Available online: https://www.mankogold.com/media/publication/98 legal-20080619.pdf (accessed on 14 March 2018).

43. AIA. D503-2013 Guide for Sustainable Projects. Available online: www.aia.org/sustainableprojectsguide (accessed on 14 March 2018).

44. Moe, K. Integrated Design in Contemporary Architecture, 1st ed.; Princeton Architectural Press: New York, NY, USA, 2008; pp. 6-9, ISBN 978-1-56898-745-3.

45. Kibert, C.J.; Sendzimer, J.; Guy, B. Construction ecology and metabolism: Natural system analogues for a sustainable built environment. Construction Management and Economics. 2010, 18, 903-916. doi:10.1080/014461900446867.

46. AIA California Council. Integration Project Delivery: An Updated Working Definition. Available online: http://www.aiacc.org/wp-content/uploads/2014/07/AIACC IPD.pdf (accessed on 14 March 20018). 